\title{
EL PROYECTO DE ACTO LEGISLATIVO 192 DE 2012: ¿POR QUÉ INVESTIGAR EN EL MARCO DEL DERECHO INTERNACIONAL HUMANITARIO?
}

Coronel Javier Ayala Amaya*.

\section{INTRODUCCIÓN.}

El conflicto armado interno que enfrenta el Estado colombiano contra los grupos criminales de las FARC y del ELN, responsables entre otros delitos de terrorismo, narcotráfico y secuestro, ha sido hoy incrementado en términos de violencia por el accionar también delictivo de las denominadas Bandas criminales emergentes (BACRIM); estos grupos, todos al margen de la Ley, incluyendo a las FARC, quienes han iniciado diálogos con el Gobierno Nacional para un posible acuerdo de Paz en medio del conflicto, requieren de una contundente respuesta armada por parte del Estado de Derecho colombiano mediante el uso de su fuerza la cual, desafortunadamente para nuestros combatientes de las FF. MM., no obstante estar regulada desde el ámbito constitucional y legal, está totalmente desprovista de unas reglas claras de enfrentamiento que le permitan al comandante militar y a la tropa en general aplicar la autoridad y la fuerza, con la absoluta tranquilidad de que su misión no solo está avalada por el gobierno nacional y por el mando sino que, también, y con toda legitimidad, esté respaldada por el Estado de Derecho en su conjunto y, en especial, por su Comandante y Jefe Supremo

\footnotetext{
"http://www.usergioarboleda.edu.co/instituto_derechos_humanos/javier_ ayala_amaya.htm. Oficial de la Reserva Activa del Ejército Nacional, Doctorando en Derecho Universidad Sergio Arboleda, Máster DD. HH. y DIH., Departamento Defensa EE.UU., Abogado CUM LAUDE y Tesis Laureada.
} 
de las Fuerzas Armadas, es decir, por el Presidente de la República de Colombia quien por su condición constitucional y jerarquía es el directo responsable de señalar unas claras reglas de enfrentamiento.

Ya sea para una misión táctica en un marco de Derechos Humanos o en un marco de hostilidades, es decir, de aplicación del D. I. H. (Derecho Internacional Humanitario). De nada, pues, servirá que el actual proyecto de Acto Legislativo que se tramita en el Congreso le facilite a la jurisdicción penal militar investigar los hechos cometidos en combate, en el marco del Derecho Internacional Humanitario, cuando en la actualidad - por condiciones políticas de por sí lamentables - se ha generado inseguridad jurídica a los militares y a los policías; entre otras medidas, se destaca un Acuerdo entre el Ministerio de Defensa Nacional y la Fiscalía General de la Nación que, según concepto de la Procuraduría General de la Nación, presentado ante el Consejo de Estado, es inconstitucional porque restringe el fuero penal militar y le da competencia a la Fiscalía General de la Nación para asumir investigaciones, cuando es evidente que los funcionarios de esta última no tienen conocimiento del derecho operacional, no dominan el derecho de la guerra ni el Derecho Internacional Humanitario e, igualmente, no tienen claridad sobre el uso de la fuerza en el contexto de la asimetría del conflicto armado colombiano sin carácter internacional. La verdad, ello permite inclusive que los militares tampoco tengan claridad sobre cuáles son las auténticas reglas de enfrentamiento a seguir, y aún esta incertidumbre es más riesgosa cuando por directivas ministeriales se les ordena combatir bandas criminales emergentes con mayor capacidad delictiva, umbral de daño y violencia que inclusive las FARC en un supuesto marco de Derechos Humanos, es decir, combatir a las bandas criminales emergentes (BACRIM) como si fueran grupos de apartamenteros. Ello, de por sí, es abiertamente contradictorio con el Derecho Internacional Humanitario.

Esta falencia de reglas de enfrentamiento claras para el uso de la fuerza por parte de nuestras tropas militares y policiales y, a su vez, la restricción de su fuero penal militar mediante el citado Convenio del Ministerio de Defensa Nacional con la Fiscalía General de la Nación, que al parecer es totalmente inconstitucional, requieren con urgencia los correctivos necesarios; para ello, es importante fortalecer el conocimiento de la incipiente disciplina denominada Derecho Operacional, todo ello por quienes combaten al terrorismo y por quienes hoy, por decisiones políticas irresponsables, tienen la competencia de investigar a los militares del Estado Colombiano, 
operadores judiciales que, como ya se dijo, nada saben de la Guerra, del DIH y, menos, de lo que es el Derecho Operacional.

Lo anterior ha contribuido a que muchos de nuestros mejores héroes, combatientes de la Patria, se vean injustamente incursos en procesos penales y disciplinarios por casos totalmente relacionados con el servicio. Pero, aún más, el desconocimiento del DICA que orienta al Derecho Internacional Humanitario y del Derecho de la Haya en el apropiado uso de los métodos y medios para conducir las hostilidades en la batalla es también notorio; ello genera, desde luego, un manto de duda e impunidad frente a la imparcialidad y a la justicia con que se desarrollan las investigaciones adelantadas por presuntas violaciones a los Derechos Humanos e infracciones al Derecho Internacional Humanitario cuando están involucrados miembros de nuestra institución militar.

\section{AsPeCTOS PARA ENTENDER POR QUÉ LOS HECHOS DE CONFLICTO} ARMADO, SIN CARÁCTER INTERNACIONAL, SE DEBEN INVESTIGAR EN EL CONTEXTO DEL DEREChO INTERNACIONAL HuMANITARIO.

- $\quad$ El DIH no es un apéndice de los Derechos Humanos.

- El DIH permite desplegar la fuerza militar con más contundencia, multiplicar el poder de las armas y de los métodos y los medios para conducir las hostilidades.

- DIH y DD.HH. son interdependientes, convergentes y necesarios pero no son iguales, no tienen el mismo lenguaje, ni los mismos interlocutores, ni llevan el mismo mensaje. La clave: entre más me acerque a las hostilidades (combate) más se aplican el DIH y sus principios. Entre más me aleje de las hostilidades cobran relevancia los DD. HH.

- El DIH, en la actualidad, no implica en un conflicto armado no internacional: a. reconocimiento de parte; $b$. reconocimiento de insurgencia, c. reconocimiento de beligerancia, d. existencia de una guerra civil.

- El DIH se aplica en un conflicto armado sin carácter internacional desde que comienzan las hostilidades hasta que culminan.

- El DIH se aplica en conflictos armados internacionales y en conflictos armados no internacionales, especialmente en situaciones que hayan superado un umbral de violencia y daño con intensidad y permanencia que los permita diferenciar de las tensiones internas y de los disturbios. 
- Existen situaciones que no cumplen con los requisitos del Protocolo II en su artículo primero, ni con los del artículo $3^{\circ}$ común en los cuatro convenios de Ginebra, ni los previstos en la jurisprudencia de tribunales internacionales; por eso no se aplica el DIH sino los Derechos Humanos. Excepcionalmente, el CICR en el texto "servir y proteger" posibilita aplicar ciertos principios del DIH respecto a la utilización de la fuerza en situaciones como las de las favelas de Brasil. Pero el contexto es totalmente diferente.

- El fuero penal militar no se defiende desde el campo de los DD. HH. Craso error, el fuero militar y las operaciones en tiempos de conflicto armado se defienden desde el DIH. El derecho operacional en un país con violencia como la colombiana no debe ser construido por quienes manejan exclusivamente DD. HH. El primer derecho que tiene un militar en tiempo de guerra es a neutralizar el objetivo militar o el blanco lícito. A un militar no se le puede compeler a no utilizar las armas del Estado, a un militar se le debe exigir aplicar el derecho de la guerra que es la médula espinal del arte de la guerra.

\section{Definición de Reglas de EnFrentamiento en un MARCo de Derecho Operacional}

Se entienden las mismas como la herramienta principal utilizada para la regulación del uso de la fuerza y sirve como piedra angular de la disciplina del derecho operacional. Su fundamento parte de la observancia del Derecho Consuetudinario y convencional en cuanto al derecho de la legítima defensa y el Derecho de la Guerra. Otros aspectos que juegan un papel esencial en la elaboración y cumplimiento de las Reglas de Enfrentamiento, son los objetivos y las limitaciones tanto de tipo político como militar.

Se le atribuye un papel de vital importancia al asesor jurídico operacional ${ }^{1}$, quien debe estar suficientemente documentado sobre los aspectos vitales de la operación tales como las armas a utilizar, los objetivos militares $\mathrm{y}$, en general, todo lo relacionado con la ley del conflicto armado.

\footnotetext{
${ }^{1}$ Grimes, Derek I. (Maj), Rawcliffe, John (Maj), Smith, Jeannine (Cpt) (Editores): Operational Law Handbook, Virginia, A Trillion Books Inc., 2006, pág. 89 [En línea]. Disponible en: http:/ / www.fas.org/irp/doddir/army/law2006.pdf [citado en 23 de noviembre 2012].
} 
Otro aspecto a resaltar es la concepción que se tiene de las Reglas de Enfrenamiento como concepto general que maneja la doctrina y otro muy particular, clasificado como "secreto", en lo que tiene que ver con aspectos específicos de una operación determinada.

De cualquier forma, se entiende que el asesor jurídico operacional deberá estar enterado en cada caso para la redacción y alcances de las Reglas de Enfrentamiento, ya sean de carácter general o las que estén cobijadas por el manto de confidencialidad que debe amparar el planeamiento de una operación específica² ${ }^{2}$

Se definen, entonces, como Reglas de Enfrentamiento, las directivas emanadas de la autoridad militar competente para delinear las circunstancias y las limitaciones bajo las cuales las fuerzas del mar, tierra y aire iniciarán y/o continuarán una confrontación con otras fuerzas combatientes ${ }^{3}$.

A. Referente histórico. Las confrontaciones de todo orden han sido tan antiguas como la misma historia del hombre desde que está sobre la faz de la tierra. En épocas remotas se presentaban discrepancias que - en no pocos casos- eran solucionadas por las vías violentas, dando lugar al culto de la barbarie donde los hombres de las cavernas arrasaban con todo lo que tuviera vida y les fuera útil. Primaba la ley del más fuerte; $\mathrm{y}$, desde luego, lo conocido como "Ley del Talión", hasta que vinieron a crearse las primeras "leyes" entendidas como "las condiciones bajo las cuales hombres independientes $y$ aislados se unieron en sociedad, hastiados de vivir en un continuo estado de guerra y de gozar de una libertad que resultaba inútil por la incertidumbre de conservarla. Sacrificaron una parte de ella para gozar del resto con seguridad y tranquilidad. La suma de todas esas constituye la soberanía de una nación"

Pero tal vez se tiene como referente de lo que fueron las primeras regulaciones en esta materia lo especificado en la Biblia "en donde Moisés estableció un conjunto de reglas para la captura, engaño, el sitiar al enemigo y el trato a los prisioneros de guerra (en aquel tiempo se mataban los hombres y se capturaban las mujeres). Un razonamiento temprano de las reglas de combate proviene de AlejandRo MAGNo, quien dijo: "¿Por qué destruir o matar lo que pronto va a ser tuyo?». Su consejo era que no

${ }^{2}$ Ibíd., pág. 89.

${ }^{3}$ Ibíd., pág. 90.

${ }^{4}$ Beccaria, Cesare: De los Delitos y de las Penas, $2^{\mathrm{a}}$. ed., Bogotá, Editorial Temis, 1990, pág, 4. 
se matara a los cautivos porque ellos más tarde pasarían a pagar tributos, a trabajar o se integrarían al ejército. En la edad media, las reglas que gobernaban las guerras empiezan a crecer a la par con el poder de la Iglesia y el ascenso de los caballeros. La caballería era un código de conducta que demandaba el ser un hombre de honor en la batalla e incluía la obligación de aceptar la rendición y el respeto a la propiedad de la iglesia. En respuesta a la declinación de la caballería como resultado de la naturaleza impersonal del desarrollo del arma de ballesta, un abogado holandés, llamado HuGo GRocio, escribió el primer código completo de leyes de la guerra en tierra, que contiene muchos de los principios básicos que se utiliza hoy en día, en especial el concepto de sufrimiento innecesario y el de blanco legítimo para atacar. El primer código sobre la ley de la guerra fue conocido en los Estados Unidos como la Orden General \# 100, el cual fue aprobado por el presidente Lincoln en el año de 1863. En función de los cambios de armas y tácticas al día de hoy, así ha tenido que cambiar la ley de la guerra. Estas leyes provienen de fuentes diversas, primariamente las convenciones de Ginebra de 1949 y las de la Haya de 1907"5.

Pero esto no estaría completo sino se conociera la posición de quienes deben estar en el campo de batalla y sufrir las vicisitudes de la guerra. Se tiene el caso de Gustavus Adolphus ${ }^{6}$ quien, en el año de 1621, escribió unos 150 artículos basados en el mantenimiento de la disciplina y la efectividad de la fuerza de combate. Por ejemplo, el artículo 100 se refería a la prohibición de quemar iglesias, hospitales y escuelas y el respeto al clero, ancianos, mujeres y niños si se probaba que ninguno de ellos contribuía a una resistencia armada. Pero, en términos generales, se tiene que reconocer que en el pasado no se hablaba mucho de unas leyes para gobernar las guerras. Esto ya no es así. En la segunda guerra mundial, los alemanes bajo el concepto de Kreigsraison, argumentaron que en ocasiones la realidad militar les permitía violentar la ley internacional, por ejemplo matar prisioneros en Malmedy por razón de que no habían previsto que iban a capturar prisioneros y no tenían un plan de manejo de los mismos y, por consiguiente, el cargar con los prisioneros ponía en

\footnotetext{
${ }^{5}$ Izquierdo, Orlando A.: Hacia un modelo de Reglas de Enfrentamiento para el Hemisferio Americano. Washington, Colegio Interamericano de Defensa, Washington D.C., 2003, págs. 9 y 10. [En línea] Disponible en: http:/ / www.docstoc.com/ docs /104987678/COLEGIO-INTERAMERICANO-DE-DEFENSA---DownloadNow-DOC [Citado en 23 de noviembre 2012].

${ }^{6}$ Gustavo II Adolfo (1594-1632), Rey de Suecia (1611-1632), apodado “El León del Norte" por su liderazgo de las fuerzas protestantes en la guerra de los Treinta Años. Biblioteca de Consulta Microsoft ${ }^{\circledR}$ Encarta ${ }^{\circledR} 2005$.
} 
peligro su ataque. Por supuesto, esta doctrina hoy es una gravísima violación a la ley internacional.

Pero hay que recordar la historia de Colombia para tener en cuenta que el primer proyecto más encomiable en esta materia nació, el 26 de noviembre de 1820, a instancias de "El Libertador", cuando él suscribió un documento de singular importancia con el llamado "Pacificador" Pablo Morillo, que se conoció como los Acuerdos de Trujillo y recibió el nombre de "Tratado de Regularización de la Guerra", que sintetizaba su pensamiento encaminado a la aplicación de una guerra regulada "con el fin de que los actos de barbarie se evitaran en la medida de lo posible"7. Ello sintetiza el pensamiento de BoLÍvAR, "cuando en varias ocasiones hizo alusión, estando Venezuela sumida en una guerra de exterminio, a la imposibilidad de conducir la guerra "Tal y como lo hacen las naciones cultas". Es decir sin actos de barbarie"s.

Lo destacable de todo esto es que fue el citado "Tratado" el resultado de las consecuencias de la respuesta de la "Guerra a Muerte" que, en su momento, libraron los españoles desde México hasta Buenos Aires con Domingo Monteverde a la cabeza, entre 1812 y 1813. Fue así como Bolívar "optó por responder, apartándose de los "preceptos" éticos del arte de la guerra, con la ley del "ojo por ojo, diente por diente". Su proclama de "guerra a muerte" significaba una guerra de exterminio, una guerra sin cuartel" por el español ya citado.

Bajo esta política fue como se tejió una de las páginas más oscuras de nuestra guerra de independencia cuando BOLÍvar, luego de sucumbir ante Boves el dos de febrero de 1814, el día 8 del mismo mes ordenó la ejecución de ochocientos prisioneros españoles. "No hubo excepciones, ni siquiera se perdonó a los pacientes de los hospitales, y la orden fue llevada a cabo en la forma más cruel"10. Justificó El Libertador tal acontecimiento al señalar que "No sólo por vengar a mi patria, sino por contener el torrente de sus destructores, estoy obligado a esta severa medida"11.

${ }^{7}$ González Pacciotti, Margarita: "Bolívar y el Arte de la Guerra", en Revista Al Margen, No. 11, 2004, pág. 7.

${ }^{8}$ Ibíd., pág. 7

${ }_{9}^{9}$ Ibíd., pág. 11.

${ }^{10}$ Cfr. Masur, Gerhard: Simón Bolívar, Trad. Pedro Martin de la Camara, México, Biografias Gandesa, Editorial Grijalbo, 1960, pág. 191.

${ }^{11}$ Lecuna Salboch, Vicente. "La Guerra a Muerte" (continuación), Boletín de la Academia Nacional de Historia, tomo XVIII, No. 69, enero-marzo de 1935, Caracas, 1935, pág. 28. 
Pero lo que debe ocupar la atención fue el verdadero alcance del "Tratado de Regularización de la Guerra" que en sus 14 artículos reglamenta el tratamiento que a partir de ese momento, 26 de noviembre de 1820, debía dársele a los prisioneros de guerra y a la población civil evitando las represalias para humanizar las consecuencias que conllevaba la gesta libertadora. Adicional a lo anterior, hay que tener en cuenta que ya para 1863, como se refiriera en anteriores párrafos, a instancias del presidente LiNCOLN, nació el Código Lieber, considerado como el primer intento de codificación de las leyes y costumbres de la guerra, aunque sólo tuvo alcance para la guerra civil norteamericana; en la práctica no fue ampliamente aplicado, si para ello se toma como ejemplo lo ocurrido en el campo de prisioneros de Andersonville, donde perecieron más de 13.000 prisioneros durante 14 meses por diversas causas, dadas las condiciones de trato y hacinamiento.

Pero un intento más consolidado se dio a instancia de Henry Dunant, como producto de su obra "Recuerdo de Solferino", cuando en 1864 se firmó el Primer Convenio de Ginebra dando lugar al primero de los documentos suscritos a instancias de la comunidad internacional para humanizar las resultas de la guerra, lo cual fue posteriormente complementado, tanto por la Declaración de San Petersburgo de 1868, como por las Convenciones de La Haya de 1899 y 1907; anótese que en 1929, en Ginebra, se suscribió otra Convención relacionada con la Guerra Terrestre, la Guerra Marítima y el Tratamiento de los Prisioneros de Guerra, pero ella no tuvo suficiente efecto ya que pocos países la ratificaron.

Centralizando el tema en lo que concierne con los conflictos armados actuales y el respeto por el derecho de gentes, se estima pertinente efectuar algunas anotaciones en relación con el desarrollo de los conflictos modernos. Por ello, Michael WALzer ${ }^{12}$ ha dicho que la visión negativa de la guerra es un enfoque moderno, pues en la antigüedad ésta era vista como una actividad legítima, desempeñada por guerreros en la que por lo general no se involucraba a la población civil ${ }^{13}$. El concepto de guerra total, en la cual la capacidad

${ }^{12}$ Cfr. Villamizar, Andrés: "Errores Militares y Reglas de Encuentro". [En línea]. Disponible en: http://www.iidh.ed.cr/comunidades/seguridad/docs/seg_ docdocumrel/reglasdeencuentro-andres-0047.pdf. Citado en 23 de noviembre 2012.

13 Walzer, Michael: Just and Unjust Wars A Moral Argument with Historical Illustrations, New York, Basic Books, 2000. 
industrial, el aparato económico y la población civil como un todo se convirtieron en un blanco del esfuerzo bélico, nació durante la Segunda Guerra Mundial, primer conflicto en el que murieron más civiles que uniformados, por lo que surgió la necesidad de establecer reglas claras de protección a los civiles y la diferenciación entre los combatientes y los no combatientes ${ }^{14}$.

Prácticamente todas las naciones del mundo, y en particular los regímenes democráticos, acatan estas normas. En este marco de limitación al uso de la fuerza surgen las reglas de encuentro ${ }^{15}$ (rules of engagement) o ROE, las cuales fueron promulgadas por primera vez de manera explícita en 1979 por parte de la Armada estadounidense, que imperan en todos los estados para regir el empleo de la fuerza letal por parte de sus fuerzas armadas ${ }^{16}$.

B. Concepto de Reglas de Enfrentamiento. El primer caso conocido de Reglas de Enfrentamiento es traído de las palabras del militar e historiador norteamericano WiLLIAM PRESCOTT ${ }^{17}$ quien advertía: "No abran fuego sino hasta que puedan verle al enemigo el blanco de la córnea del ojo". Parecieran extremos estos ejemplos en los tiempos actuales pero no deja de ser muy diciente que desde el siglo XVIII, ya existía preocupación sobre las regulaciones que debían observar los combatientes en el campo de batalla, así la historia enseñe que fueron más las atrocidades y desmanes que se cometieron que la observancia de un patrón humanitario ante la eventualidad de una confrontación bélica. De cualquier forma, se anota que el ámbito evolutivo de las Reglas de Combate pudo tener origen, en la historia reciente, en Malta en los años sesenta y que su fundamento radica en ser una herramienta mediante la cual las "Autoridades de Nacionales de Mando y los comandantes operacionales tratan de ejercer control sobre el uso de la fuerza en una crisis o de controlar un conflicto"18.

\footnotetext{
${ }^{14}$ Idem. Si bien la noción de la diferenciación entre los combatientes y los no combatientes había surgido desde la Primera Guerra Mundial, fue la devastación causada por la Segunda la que la posibilitó.

${ }^{15}$ Cfr. Villamizar, Op. cit., pág. 2. El término original anglosajón, rules ofengagement es generalmente traducido al español como reglas de enfrentamiento. Sin embargo aquí se emplea la expresión reglas de encuentro, porque precisamente una de sus funciones es la de ayudar a determinar si debe haber enfrentamiento o no, por lo que la expresión reglas de enfrentamiento indicaría erróneamente que solo se emplean durante el combate.

16 Villamizar, Op. cit., pág. 2.

${ }^{17}$ Hickling, William, t. 1726-1795.

${ }^{18}$ Grimes/Rawcliffe/Smith, pág. 67.
} 
La reglamentación que sobre la materia trae el "Manual de Derecho Internacional Operacional" las define como las directrices que la autoridad militar, por competencia, emite para delinear las circunstancias y limitaciones bajo las cuales sus fuerzas navales, de tierra y del aire originarán o proseguirán combate con el enemigo ${ }^{19}$. Aunque es de anotar que la misma doctrina trae un concepto más amplio al señalar que "Son directivas que un gobierno puede establecer para delinear las circunstancias y limitaciones bajo las cuales sus fuerzas navales, terrestres y aéreas entablarán combate con el enemigo y proseguirán la lucha con el mismo"20.

La Guerra del Golfo demostró que los jefes civiles y militares norteamericanos habían aprendido las lecciones importantes aportadas por la Guerra de Vietnam. La existencia de un reglamento de combate bien definido tuvo un papel destacado en este éxito. Por eso, las operaciones norteamericanas en el Golfo se parecían muy poco a las de Vietnam, donde las restricciones impuestas a la selección de objetivos y a las tripulaciones aéreas estorbaban de manera irrazonable e innecesaria la eficacia militar y aumentaban los riesgos que enfrentaban dichas tripulaciones. Los esfuerzos por educar al personal en materia de derecho bélico han tenido éxito. El respeto por las leyes aplicables a las operaciones de guerra y el trato humano del que fueron objeto los soldados y civiles iraquíes, fueron indispensables para mantener el apoyo de la opinión pública nacional e internacional. Y lo que es aun más importante, proceder como se hizo fue lo correcto. El ejercicio del derecho operacional tuvo un papel importante en el éxito de esta campaña ${ }^{21}$.

Esta definición se ajusta un poco más a lo que se quiere mostrar y es la estricta subordinación de la autoridad militar ante la civil; la que en últimas, bajo su responsabilidad, emite las políticas dentro de las cuales se encausará el despliegue de la fuerza, observando eso sí, un claro respeto por las normas mínimas de humanidad o de lo contrario se caería en los extremos vividos en el conflicto de los Balcanes o algunas naciones africanas, donde se caracterizó

\footnotetext{
${ }^{19}$ Grimes/Rawcliffe/Smith, idem, pág. 67.

${ }^{20}$ Idem, pág. 67.

${ }^{21}$ Humphries, John G.: "El Derecho operacional y el reglamento de combate. en las operaciones escudo del desierto y tormenta del desierto". [En línea]. Disponible en: http:/ /www.airpower.au.af.mil/apjinternational/apj-s/1993/2trimes93/ humphries.html [citado en 23 de noviembre 2012].
} 
la política estatal por desconocer el mínimo humanitario frente a quienes iban en contra de sus designios.

Por eso, se comparte lo que otra fuente doctrinaria enseña: "Las Reglas de Enfrentamiento se definen como directivas establecidas por una autoridad competente y de rango superior que delimitará las circunstancias y limitaciones bajo las cuales las fuerzas militares iniciarán o continuarán el combate con otras fuerzas"22. Siguiendo los conceptos del autor citado, es imperioso puntualizar que al fijar tales Reglas, ellas deben descansar en los postulados del Derecho Internacional de los Conflictos Armados (DICA), armonizados con la política pública del país, la opinión pública y la restricción en las operaciones militares ${ }^{23}$. Estos últimos aspectos juegan un papel primordial al momento de deslindar responsabilidades que bien pudieran, a priori, cuestionar la ejecución de la misión por parte del personal de las Fuerzas Armadas.

No se debe pasar por alto, lo que sobre este particular ha señalado el Comité Internacional de la Cruz Roja al precisar que: "Son un mecanismo básico para que los mandos superiores decidan cuando se debe desplegar una fuerza militar y cuánta fuerza se puede emplear. Determinar el grado y las modalidades de aplicación de la fuerza, así como los limites dentro de los cuales puede actuar un jefe. Se pueden trazar reglas de enfrentamiento para restringir acciones concretas o para ampliar los limites de una acción, sin dejar de aplicar el derecho internacional. Las reglas de enfrentamiento son la suma de varios factores, que incluyen el marco jurídico de las operaciones, instrucciones politicas y misión militar".

Por ello, es justificable y merece respaldo el artículo $3^{\circ}$ del Proyecto de acto legislativo No. 16 de 2012 Senado, 192 de 2012 Cámara, "por el cual se reforman los artículos 116, 152 y 221 de la Constitución Política de Colombia", que en su tercer párrafo expresa lo siguiente: "Cuando la conducta de los miembros de la Fuerza Pública en relación con un conflicto armado sea investigada y juzgada por las autoridades judiciales, se aplicará siempre el Derecho Internacional Humanitario. Una ley especificará sus reglas de interpretación y aplicación, y determinará la forma de armonizar el derecho penal con el Derecho Internacional Humanitario."

${ }^{22}$ Izquierdo, Op. cit., pág. 11.

${ }^{23}$ Ibíd. 
Y, como solución a este propósito, de contar con una ley que especifique reglas de interpretación y aplicación y que determine la forma de armonizar el Derecho penal con el Derecho Internacional Humanitario, hemos considerado oportuno y necesario desde la Escuela de Derecho de la Universidad Sergio Arboleda impulsar, apoyar, y acompañar académicamente la iniciativa legal denominada: PROYECTO DE LEY 166 DE 2011 CÁMARA, 19 DE 2011 SENADO. "Por la cual se establecen políticas públicas que implementen el derecho operacional en el marco de la garantía y el respeto de los Derechos Humanos y del Derecho Internacional Humanitario por parte de las Fuerzas Militares y Policía Nacional“. Propuesta radicada por el Honorable Senador MAnuel Virguez en la Comisión Segunda Constitucional y en Comisión segunda de la Cámara por el Honorable Representante Juan Carlos Martínez GutiérRez. Su finalidad es promover la aplicación del derecho operacional, definir políticas que garanticen el respeto y el cumplimiento de los Derechos $\mathrm{Hu}$ manos (DDHH) y el DIH durante la conducción de las operaciones y el desarrollo de operativos por parte de las Fuerzas Militares y la Policía Nacional, en el marco de las hostilidades de cara al mantenimiento de la seguridad interna; identificar los regímenes jurídicos que rigen las operaciones militares y operativos policiales en virtud de los diferentes contextos operacionales; determinar la reglamentación que regule los procesos y procedimientos de la presente ley; precisar las fuentes y aplicación de los recursos necesarios para su implementación.

Proyecto de ley que, para efectos académicos, me permito anexar a este texto de cara a facilitar su análisis y estudio. Es posible que en esta fecha en que desarrollemos el panel haya sido archivado luego de la votación en la Comisión Segunda de Cámara o que haya pasado y solo quede pendiente, finalmente, ser radicado ante la plenaria de la Cámara de Representantes. Lo anterior porque fue radicado en Senado y pasó, tanto en la Comisión Segunda como en la plenaria del mismo con votación positiva y contundente.

AneXo.

“TEXTO PROPUESTO PARA PRIMER DEBATE CÁMARA AL PROYECTO DE LEY NÚMERO 19 DE 2011 SENADO, 166 DE 2011 CÁMARA

Por la cual se establecen politicas públicas que implementen el derecho operacional en el marco de la garantía y el respeto de los Derechos Humanos y del Derecho Internacional Humanitario por parte de las Fuerzas Militares y Policía Nacional. 


\section{DECRETA:}

Artículo $1^{\circ}$. Objeto. La presente ley establece criterios de implementación y la aplicación del derecho operacional para el cumplimiento de la misión Constitucional encargada a la Fuerza Pública, mediante la identificación de los regímenes jurídicos que rigen las operaciones militares y operativos policiales en los diferentes contextos operacionales.

Artículo $2^{\circ}$. Definición de Derecho Operacional. El derecho operacional corresponde al conjunto de normas jurídicas, nacionales e internacionales debidamente incorporadas al ordenamiento interno, y directrices gubernamentales que regulan el empleo de la fuerza por parte de los miembros de las Fuerzas Militares y la Policía Nacional, en cumplimiento de sus misiones Constitucionales y conforme las particularidades de cada contexto operacional.

Artículo $3^{\circ}$ : Glosario. Para efectos de la presente ley, se entenderá por los siguientes términos:

Conflicto armado internacional. Confrontación armada entre las fuerzas armadas de dos o más Estados contendores.

Conflicto armado sin carácter internacional. Es el que tiene lugar en el territorio de un Estado entre sus Fuerzas Armadas y fuerzas armadas disidentes o grupos armados organizados o entre estos.

Contextos operacionales. Escenarios circunstanciales, dinámicos y complejos, en el que las Fuerzas Militares y la Policía Nacional conducen operaciones o desarrollan operativos en procura de contrarrestar las afectaciones o amenazas a la soberanía, la integridad territorial, el orden constitucional y la seguridad interna, reglados por regímenes jurídicos específicos que condicionan diferencialmente el empleo de la fuerza por parte de sus miembros.

Labores de defensa. Acciones tendientes a preservar la soberanía, la independencia, la integridad del territorio nacional y del orden constitucional, de amenazas o agresiones externas o internas.

Labores para el mantenimiento de la seguridad o el orden público interno. Acciones tendientes primordialmente a la prevención, detección y combate del delito y demás factores de desestabilización del orden y la convivencia ciudadana, de manera que se den las condiciones necesarias para el ejercicio de los derechos y libertades públicas.

Objetivo militar. Constituye un objetivo militar a la luz del Derecho Internacional Humanitario (DIH) los combatientes ¿tratándose de conflictos armados internacionales? , así como quienes asuman una función continua de combate o participen directamente en las hostilidades por el tiempo en que dure la misma. Asimismo, aquellos bienes que por su naturaleza, ubicación, finalidad o utilización contribuyan eficazmente a la acción del enemigo o cuya destrucción total o parcial, captura o neutralización ofrezcan en las circunstancias del caso, una ventaja militar definida.

Ventaja militar. Provecho estratégico, operacional o táctico que subyace y motiva el desarrollo de una operación militar en el marco de las hostilidades, representado en la correlativa afectación a los intereses o la capacidad del enemigo. 
Artículo $4^{\circ}$ : Finalidad. La presente ley tiene como finalidad promover la aplicación del derecho operacional, definir políticas que garanticen el respeto y el cumplimiento de los Derechos Humanos (DDHH) y el DIH durante la conducción de las operaciones y el desarrollo de operativos por parte de las Fuerzas Militares y la Policía Nacional, en el marco de las hostilidades y en el mantenimiento de la seguridad interna; identificar los regímenes jurídicos que rigen las operaciones militares y operativos policiales en virtud de los diferentes contextos operacionales; determinar la reglamentación que regule los procesos y procedimientos de la presente ley; determinar las fuentes y aplicación de los recursos necesarios para su implementación.

Artículo $5^{\circ}$. Principios Generales. Serán principios orientadores de la presente ley:
a) El de la dignidad humana;
b) El de no discriminación;
c) El de Legalidad;
d) El de solidaridad;
e) El de especificidad funcional;
f) El de coordinación interinstitucional;
g) El de buena fe.

Artículo $6^{\circ}$. Propósito de las Operaciones Militares y los Operativos Policiales. Las operaciones militares y los operativos policiales, tienen como propósito fundamental el de coadyuvar al cumplimiento de los fines del Estado, el logro de los objetivos de defensa y el mantenimiento de la seguridad interna, en función de los ámbitos específicos de competencia institucionales.

Artículo $7^{\circ}$. Contextos Operacionales. En cumplimiento de sus misiones constitucionales, la Fuerza Pública conduce operaciones en desarrollo de hostilidades y llevan a cabo operativos para el mantenimiento de la seguridad interna. La identificación de cada uno de estos contextos operacionales en la planeación de dichas actividades determina el régimen jurídico específico aplicable a su ejecución y evaluación, regulando el empleo de la fuerza.

Parágrafo. Con sujeción a las disposiciones de la presente ley, corresponde a las Fuerzas Militares y a la Policía Nacional el deber de establecer, definir y regular, por vía de la expedición de manuales o reglamentos, -en los que se dicten reglas claras para el empleo de la fuerza-, el tipo de operaciones y operativos a desarrollar por parte de sus unidades en los diferentes contextos operacionales.

Artículo $8^{\circ}$. Ámbitos Funcionales y Asistencia Interinstitucional. En virtud de los ámbitos funcionales establecidos en los artículos 217 y 218 de la Constitución Política de Colombia y los principios generales de legalidad, especificidad funcional y coordinación interinstitucional que fundamentan la presente ley, la conducción de operaciones militares en el marco de hostilidades corresponde primordialmente a las Fuerzas Militares, en tanto que las labores para el mantenimiento de la seguridad interna corresponde a la Policía Nacional.

Esto no obsta para que excepcionalmente, dada la dinámica y gravedad de los fenómenos desestabilizadores del orden público o las hostilidades, las Fuerzas Militares puedan desarrollar operaciones para el mantenimiento de la seguridad o prestar su asistencia a las unidades policiales y la Policía Nacional llevar a cabo operativos en el marco de las hostilidades. 
Parágrafo $1^{\circ}$. Cuando por una medida excepcional las Fuerzas Militares adelanten operaciones de mantenimiento de la seguridad o la Policía Nacional conduzca operativos en desarrollo de las hostilidades, el Ministerio de Defensa Nacional deberá garantizar se cuente con los medios y el entrenamiento apropiado para evitar se falte a la misión constitucional encomendada o poner en indebido riesgo la vida e integridad de los funcionarios.

Parágrafo $2^{\circ}$. El Ministerio de Defensa Nacional implementará un sistema de instrucción y entrenamiento especial para el empleo diferenciado de la fuerza por parte del personal militar y policial, en los dos contextos operacionales de que trata el presente artículo.

Artículo $9^{\circ}$. Código de Conducta. El Gobierno Nacional, a través del Ministerio de Defensa Nacional presentará la iniciativa legal de un Código de conducta operacional para las Fuerzas Militares y para la Policía Nacional, que garantice un adecuado uso de la Fuerza en los distintos contextos operacionales.

Artículo 10. Régimen jurídico aplicable en el Mantenimiento de la Seguridad Interna. Los operativos u operaciones que desarrollen la Policía Nacional y las Fuerzas Militares para el mantenimiento de la seguridad interna, en relación con sus ámbitos competenciales, están regidas por las normas que integran el Derecho Internacional de los Derechos Humanos, las leyes nacionales que las incorporan, normas de naturaleza penal, reglamentos y manuales, que regulan la respuesta institucional al fenómeno criminal, así como otras alteraciones al orden público interno o afectaciones a la convivencia ciudadana pacífica.

El empleo de la fuerza en este contexto, en virtud al régimen jurídico de que trata el presente artículo se rige por los principios específicos de gradualidad, necesidad, proporcionalidad y legalidad.

Parágrafo $1^{\circ}$. Principio específico de gradualidad. El uso de la fuerza y de las armas de fuego por parte de los funcionarios encargados que cumplan labores de mantenimiento de la seguridad, constituye un recurso excepcional. Ello supone el uso reactivo, diferenciado y gradual de la fuerza, que involucra desde medidas disuasivas o acciones no violentas hasta el recurso excepcional del empleo letal de las armas de fuego.

Parágrafo $2^{\circ}$. Principio Específico de Necesidad. El empleo de la fuerza se justifica en situaciones en que por sus circunstancias particulares resulte ser inevitable.

Se entiende como inevitable el uso de la fuerza (inclusive mediante el empleo de armas de fuego), generalmente, ante ineficacia de las medidas disuasivas o la imposibilidad de asegurar el resultado legítimo previsto, y, específicamente:

a) En los eventos descritos por las causales 5 y 6 de ausencia de responsabilidad que prevé el artículo 32 del Código Penal Colombiano;

b) Para evitar la comisión de un delito especialmente grave que constituya actual o potencial amenaza para la vida;

c) Con el fin de lograr la detención o impedir la fuga de una persona que represente dicho peligro o preste resistencia física.

En estos casos, los funcionarios encargados de llevar a cabo labores para el mantenimiento de la seguridad, deberán identificarse como tales, advirtiendo claramente su intención dehacer uso de sus armas de fuego, con el tiempo suficiente para ser tomada en cuenta, a menos que con ello se ponga indebidamente en 
peligro su vida e integridad física o la de otras personas, o resultara evidentemente inadecuado o inútil conforme las particularidades de caso.

Parágrafo $3^{\circ}$. Principio específico de proporcionalidad. El uso de la fuerza, inclusive mediante el empleo de las armas de fuego, debe ser proporcionado en relación con la gravedad del peligro o la agresión, actual o inminente, que se requiere repeler o el objetivo legítimo que se persiga alcanzar. Supone una ponderación entre la entidad del peligro o la agresión y la fuerza empleada para evitarlo o repelerlo.

Parágrafo $4^{\circ}$. Principio específico de legalidad. El empleo de las armas en desarrollo de operaciones militares $\mathrm{u}$ operativos policiales para el mantenimiento de la seguridad interna, impone a los funcionarios el deber de observar los estándares de regulación y manejo establecidos por las normas nacionales e internacionales vigentes que integran el Derecho Internacional de los Derechos Humanos, las normas de naturaleza penal y de policía, así como los reglamentos y manuales internos.

Artículo 11. Régimen Jurídico Aplicable en la Conducción de Hostilidades. Las operaciones $\mathrm{u}$ operativos de naturaleza militar que conduzcan las Fuerzas Militares y la Policía Nacional en desarrollo de las hostilidades, en relación con sus ámbitos competenciales, están regidas por las normas que integran el Derecho Internacional aplicable a los Conflictos Armados, las leyes nacionales que las incorporan, los reglamentos y manuales.

En el marco de este contexto, está legitimado el empleo anticipado y no gradual de la fuerza respecto de personas y/o bienes que constituyan objetivo militar a la luz del DIH y con fundamento en los principios específicos de humanidad, necesidad militar, distinción, limitación, proporcionalidad y no intervención.

Parágrafo $1^{\circ}$. Principio específico de humanidad. Las personas civiles que no intervengan directamente en las hostilidades y quienes hayan sido puestas fuera de combate gozan de protección contra ataques directos.

Parágrafo $2^{\circ}$. Principio específico de necesidad militar. El desarrollo de las operaciones $u$ operativos de naturaleza militar en el marco de las hostilidades debe obedecer a la búsqueda de una ventaja de orden estratégico, operacional o táctico, en virtud de la cual se legitima el uso de medios o métodos de guerra no prohibidas por el Derecho Internacional aplicable a los Conflictos Armados.

Parágrafo $3^{\circ}$. Principio Específico de Distinción. Durante el planeamiento y la ejecución de las operaciones u operativos de naturaleza militar, deberá distinguirse entre los combatientes y los no combatientes, de igual manera se deberá distinguir entre quienes ostentan una función continua de combate o participan directamente en las hostilidades y quienes no lo hacen. Asimismo, se deberá hacer distinción entre los bienes civiles y los que constituyen objetivos militares.

Parágrafo $4^{\circ}$. Principio Específico de Limitación. La elección de los medios y métodos de combate no es ilimitada. No se podrán utilizar armas que puedan causar males superfluos, sufrimientos innecesarios o daños extensos, duraderos, y graves al medio ambiente natural.

Parágrafo $5^{\circ}$. Principio Específico de Proporcionalidad. Las operaciones $\mathrm{u}$ operativos de naturaleza militar no deben causar daños en personas o bienes civiles, que resulten excesivos en relación con la ventaja militar concreta y 
directa prevista. Supone entonces, una ponderación entre la ventaja militar y los daños incidentales que puedan producirse en personas y bienes que no constituyan objetivo militar a la luz del Derecho Internacional Humanitario.

Parágrafo $6^{\circ}$. Principio Específico de no Intervención. No podrán invocarse las normas del DIH, con el objeto de menoscabar la soberanía de un Estado o la responsabilidad que le incumbe al Gobierno de mantener o restablecer la ley y el orden en el Estado o de defender la unidad nacional y la integridad territorial del Estado por todos los medios legítimos, como tampoco para intervenir directa e indirectamente en el conflicto armado o en los asuntos internos o externos del Estado.

Artículo 12. Integración Interinstitucional. El Gobierno Nacional liderará la participación e integración de las Fuerzas Militares y de la Policía Nacional, en encuentros interinstitucionales de DDHH, DIH y Derecho Operacional. Tales espacios, permiten mantener actualizados a los miembros de la Fuerza Pública, sobre los temas más significativos y prioritarios de la agenda, así como en aspectos concernientes a su promoción, protección, y garantía; interviniendo en escenarios de formulación de políticas de prevención, atención y de respuesta, a requerimientos originarios de diversas instancias del orden nacional e internacional.

Parágrafo. La integración contempla tareas como: relaciones interinstitucionales, educación en DDHH y DIH para la población civil, acercamientos con Organizaciones No Gubernamentales de Derechos Humanos, y trabajo coordinado y mancomunado con las autoridades civiles del Estado, facilitando un adecuado proceso de atención y trámite de quejas.

Artículo 13. Transversalización del Derecho Operacional. Los reglamentos y manuales vigentes o que expidan las Fuerzas Militares y la Policía Nacional para regular el uso de la fuerza en desarrollo de las hostilidades y el mantenimiento de la seguridad interna, deben ser debidamente transversalizados con los criterios previstos en la presente ley.

Artículo 14. Implementación de Políticas. El Gobierno Nacional implementará las políticas necesarias para el desarrollo del Derecho Operacional, como una herramienta indispensable que facilite el cumplimiento de la misión constitucional de la Fuerza Pública.

Parágrafo $1^{\circ}$. El Gobierno Nacional a través del Ministerio de Defensa Nacional, en coordinación con el Comando General de las Fuerzas Militares y la Dirección General de la Policía Nacional, implementará reglas generales de empleo de la fuerza en los contextos operacionales de que trata la presente ley, en el marco del régimen jurídico correspondiente, igualmente implementará una estrategia de educación y entrenamiento práctico al respecto.

Parágrafo $2^{\circ}$. El Gobierno Nacional a través del Ministerio de Defensa Nacional presentará la iniciativa legal de un Código de conducta operacional para las Fuerzas Militares y para la Policía Nacional, que garantice un adecuado uso de la Fuerza.

Artículo 15. Regulación. El Gobierno Nacional a través del Ministerio de Defensa Nacional, establecerá mecanismos para realizar un continuo seguimiento a la gestión desarrollada por la Fuerza Pública en materia de DDHH y $\mathrm{DIH}$, para lo cual verificará que esta ejerza sus actuaciones en obedecimiento incondicional a las normas jurídicas que delimitan su campo de maniobra. 
Artículo 16. Recursos. El Gobierno Nacional asignará recursos con destinación específica para el entrenamiento, equipamiento, capacitación e instrucción en Derecho Operacional.

Artículo 17. Promoción de la Educación y Prevención de la Violación de los DDHH e infracción al DIH en el Marco del Derecho Operacional. El Gobierno Nacional implementará mecanismos para que el Ministerio de Defensa Nacional con apoyo del sector empresarial, otorgue recursos para el fortalecimiento académico en Educación y Prevención a la Violación de los DDHH e infracción al DIH en el marco del Derecho Operacional a través de instituciones nacionales y extranjeras del personal de la Fuerza pública. De igual manera el Gobierno Nacional con el apoyo de las Fuerzas Militares, implementará programas de formación en Derecho Operacional a la Fiscalía General de la Nación, los Jueces de la República, la Procuraduría General de la Nación y los Defensores Públicos.

Parágrafo $1^{\circ}$. La prevención se concibe como el conjunto de estrategias coordinadas por las Fuerzas Militares y la Policía Nacional tendientes a evitar la ocurrencia de violaciones a los DDHH e infracciones al DIH, desactivar las amenazas y/o mitigar los efectos generados por su ocurrencia y a brindar garantías de no repetición, teniendo como eje transversal el enfoque diferencial.

Parágrafo $2^{\circ}$. La educación, el entrenamiento y la difusión que se genere con estos recursos, se deberán brindar transversalmente en toda la Ciencia Militar y Policial y se dirigirá a todos los niveles del mando de las Fuerzas Militares y de la Policía Nacional, y para ello se integrarán en todos los cursos de formación, la educación y la enseñanza de los DDHH, el DIH y el Derecho Operacional, aspectos básicos para el fortalecimiento de la democracia.

Artículo 18. Defensa Técnica. El Gobierno Nacional implementará mecanismos para garantizar el derecho fundamental a la Defensa Técnica de los miembros de la Fuerza Pública.

Artículo 19. Juzgamiento por Violación de los DDHH e Infracción al DIH. El Consejo Superior de la Judicatura designará jueces especializados, con especial conocimiento y experiencia sobre la doctrina militar y policial, para el juzgamiento de los miembros de la fuerza pública por presuntas violaciones a los Derechos Humanos e infracciones al Derecho Internacional Humanitario en los casos que no sea competencia de la justicia penal militar.

Artículo 20. Vigencia y Derogatorias. La presente ley rige a partir de la fecha de su publicación y deroga las disposiciones que le sean contrarias.

Ponente,

Juan Carlos Martínez Gutiérrez

Representante Valle del Cauca". 